\title{
Methods Improving Energy Efficiency of Photovoltaic Systems Operating under Partial Shading
}

\author{
Pavel Kuznetsov ${ }^{1, *(1)}$, Leonid Yuferev ${ }^{2}$, Dmitry Voronin ${ }^{3}{ }^{\circledR}$, Vladimir A. Panchenko ${ }^{2,4}{ }^{\oplus}$, Michał Jasiński ${ }^{5}{ }^{\circledR}$, \\ Arsalan Najafi ${ }^{5}(\mathbb{D})$, Zbigniew Leonowicz ${ }^{5}\left(\mathbb{D}\right.$, , Vadim Bolshev ${ }^{2}\left(\mathbb{D}\right.$ and Luigi Martirano ${ }^{6}$ (D) \\ 1 Institute of Nuclear Energy and Industry, Sevastopol State University, 299053 Sevastopol, Russia \\ 2 Federal State Budgetary Scientific Institution "Federal Scientific Agroengineering Center VIM", \\ 109428 Moscow, Russia; leouf@ya.ru (L.Y.); pancheska@mail.ru (V.A.P.); vadimbolshev@gmail.com (V.B.) \\ 3 The National Technology Initiative Institute, Sevastopol State University, 299053 Sevastopol, Russia; \\ voronin@sevsu.ru \\ 4 Department of Theoretical and Applied Mechanics, Russian University of Transport, 127994 Moscow, Russia \\ 5 Faculty of Electrical Engineering, Wroclaw University of Science and Technology, 50-370 Wroclaw, Poland; \\ michal.jasinski@pwr.edu.pl (M.J.); arsalan.najafi@pwr.edu.pl (A.N.); zbigniew.leonowicz@pwr.edu.pl (Z.L.) \\ 6 Department of Astronautical, Electrical and Energy Engineering (DIAEE), Sapienza University of Rome, \\ 00184 Rome, Italy; luigi.martirano@uniroma1.it \\ * Correspondence: pavelnik2@gmail.com
}

check for

updates

Citation: Kuznetsov, P.; Yuferev, L. Voronin, D.; Panchenko, V.A.; Jasiński, M.; Najafi, A.; Leonowicz, Z.; Bolshev, V.; Martirano, L. Methods Improving Energy Efficiency of Photovoltaic Systems Operating under Partial Shading. Appl. Sci. 2021, 11, 10696. https://doi.org/10.3390/ app112210696

Academic Editor: Allen M. Barnett

Received: 30 September 2021

Accepted: 9 November 2021

Published: 12 November 2021

Publisher's Note: MDPI stays neutral with regard to jurisdictional claims in published maps and institutional affiliations.

Copyright: (c) 2021 by the authors. Licensee MDPI, Basel, Switzerland. This article is an open access article distributed under the terms and conditions of the Creative Commons Attribution (CC BY) license (https:// creativecommons.org/licenses/by/ $4.0 /)$.
Abstract: This article is devoted to the relevant problem of increasing the efficiency of PV systems. The presented analysis discusses the available methods for improving the power generation of PV modules under partial shading. Mathematical models for power loss calculation were compiled based on the results of this analysis. The proposed approach minimizes the negative impact of partial shading on the energy production of PV modules. It is based on the equalization of voltages of parallel-connected arrays of modules by installing additional power elements in them. The proposed solution is promising for various areas; it allows for the minimization of the unfavorable influence of existing urban objects (buildings, trees, communications, etc.) on the energy efficiency of PV modules. The obtained results are useful for the sustainable development of the urban environment in the context of digital transformation. They are the basis for the promising methodology of the parametric optimization of power plants using renewable energy sources.

Keywords: PV systems; efficiency; renewable energy sources; shading; maximum power point

\section{Introduction}

Renewable-energy power plants are increasingly widespread in the world. Solar power plants are the most promising due to environmental friendliness and solar radiation availability. The amount of radiation density differs no more than twice depending on the location [1]. Moreover, the modular design of photovoltaic (PV) plants allows them to be designed for almost any power, making them a versatile and reliable solution that is widely used both in industrial power generation and in small power supply systems [2].

The design features of many solar installations lead to the appearance of the effect of long-term partial shading of individual PV modules [3]. The use of such schemes is associated with the limited area of the projected installation, the desire to save space, or the properties of the relief. At the same time, some operation features of PV modules are not taken into account, which leads to a significant decrease of efficiency [4]. Uneven illumination of PV modules can also occur due to factors independent of design. Examples of such cases are shadowing due to nearby buildings, trees, clouds, and others. Many authors pay a lot of attention to this scientific problem in their works [5-10].

To achieve the required electrical power, solar power plants use different commutation types of solar cells, such as series, parallel, and mixed. The effect of partial shading on the efficiency of PV installations significantly depends on the switching option. When 
developing effective solutions, it is necessary to find a compromise between cost and functionality. There is a significant increase of the amount of solar power plants in recent years $[1,2]$. The relevance of the problem considered in this article is beyond doubt because $70 \%$ of PV installations have a design with a multi-row arrangement of solar panels with an inherent problem of shading the lower rows at low solar heights [11].

The existing methods for increasing the efficiency of shaded PV installations have a number of features that limit their unconditional application. Such methods include the use of shunt diodes, individual DC-DC converters (ICP), micro-inverters, reconfigurable switching systems, and differential power take-off systems. In this regard, to assess the effectiveness of their implementation, it is necessary to create mathematical models, the solutions of which are the values of energy losses of solar installations with various options for switching solar cells and methods of taking electrical energy.

The authors have analyzed the existing methods of increasing the energy efficiency of PV installations with partial shading. Mathematical models have been developed that allow the calculation of the values of power losses when using various methods to improve energy efficiency. An effective method for increasing the power generation of partially shaded PV installations with mixed commutation is proposed. The method consists of voltage matching of parallel-connected arrays of solar cells. With partial shading of one PV module from an array formed by eighteen modules, the application of the method will increase the average daily energy production by $19.7 \%$, with shading of two by $43.7 \%$.

\section{Materials and Methods}

The proposed scientific results are based on a set of analytical and experimental research methods, including mathematical modeling, the "light equivalent" method, and methods of mathematical processing of the experimental results. The works [12-18] are the theoretical and methodological basis of this research.

For a theoretical analysis of the processes occurring in PV installations with various switching options for solar cells operating in conditions of uneven illumination, a mathematical model of a solar cell was compiled, with an accuracy sufficient for engineering calculations-not exceeding the design tolerance. Thus, the initial mathematical model describing the operation of the solar cell model is as follows [19-21].

$$
I=I_{p h}-I_{0}\left[\exp \left(\frac{q\left(U+I R_{s}\right.}{\mathrm{A} k T}\right)-1\right]-\frac{U+I R_{s}}{R_{s h}},
$$

where $I$ is theoutput current of the solar cell, $(\mathrm{A}) ; I_{p h}$ is the photocurrent of the solar cell, (A); $I_{0}$ is the reverse saturation current of the solar cell, (A); $q$ is the electron charge, $\left(1.602 \cdot 10^{-19} \mathrm{C}\right) ; U$ is the voltage at the output of the solar cell, $(\mathrm{V}) ; k$ is the Boltzmann constant $\left(1.381 \cdot 10^{-23} \mathrm{~J} / \mathrm{K}\right) ; T$ is the temperature of the solar cell, $(\mathrm{K}) ; R_{s}$ is the series resistance of the solar cell, $(\Omega) ; R_{s h}$ is the parallel resistance of the solar element, $(\Omega)$; A is the ideality factor, depending on the thickness of the p-n-junction and the material, takes values for silicon PEC from 1.2 to 5 (Table 1).

Table 1. Ideality factor of the solar cell from material [22-24].

\begin{tabular}{cc}
\hline Material & Coefficient A \\
\hline Si-monocrystalline & 1.2 \\
Si-polycrystalline & 1.3 \\
a-Si:H-amorphous hydrogenated & 1.8 \\
a-Si:H double & 3.3 \\
a-Si:H triple & 5 \\
\hline
\end{tabular}

The photocurrent $\left(I_{p h}\right)$ can be calculated from the short circuit current under various lighting and temperature conditions by dividing the current, assuming that during a short 
circuit the current flowing through the diode is negligible and almost all of the generated current flows into the load. According to this:

$$
I_{p h}=\left[I_{s c(s t c)}+K_{i}\left(T-T_{s t c}\right)\right] \frac{\beta}{\beta_{s t c}} \cdot \frac{R_{s h}+R_{s}}{R_{s h}},
$$

where $K_{i}$ is the temperature coefficient of the short-circuit current of the solar cell, (A/K); $\beta$ is the intensity of solar radiation $\left(\mathrm{W} / \mathrm{m}^{2}\right) ; \beta_{s t c}$ is the intensity of solar radiation at standard test conditions $\left(\mathrm{W} / \mathrm{m}^{2}\right) ; I_{s c(s t c)}$ is the short-circuit current in standard test conditions (A); $T_{s t c}$ is the temperature at standard test conditions ( $\left.298 \mathrm{~K}\right)$.

The reverse saturation current $I_{0}$ depends significantly on the temperature of the solar cell, while the change in the photocurrent is not so great. As a result of an increase in temperature, the height of the potential barrier decreases, and the concentration of minority charge carriers grows exponentially, which leads to an increase in the photocurrent. The amount of reverse current is also influenced by the structure and material of the solar cell. Thus, the reverse saturation current can be calculated from Equation (1) solved for the open circuit point:

$$
I_{0}=\frac{I_{p h}}{\exp \left[\frac{q\left[U_{o c}+K_{u}\left(T-T_{s t c}\right)\right]}{\mathrm{A} k T}\right]-1},
$$

where $K_{u}$ is the temperature coefficient of open circuit voltage $(\mathrm{V} / \mathrm{K}) ; U_{o c}$ is the open circuit voltage $(\mathrm{V})$.

To assess the energy efficiency of PV installations, an information-measuring complex was proposed as a tool. The block diagram of the complex is shown in Figure 1. It allows automatic load regulation with simultaneous measurement, registration, and graphical display of voltage and current values. In addition, this complex allows you to measure and record the temperature of the environment and the surface of solar cells by the pyrometric method, as well as the intensity of solar radiation.

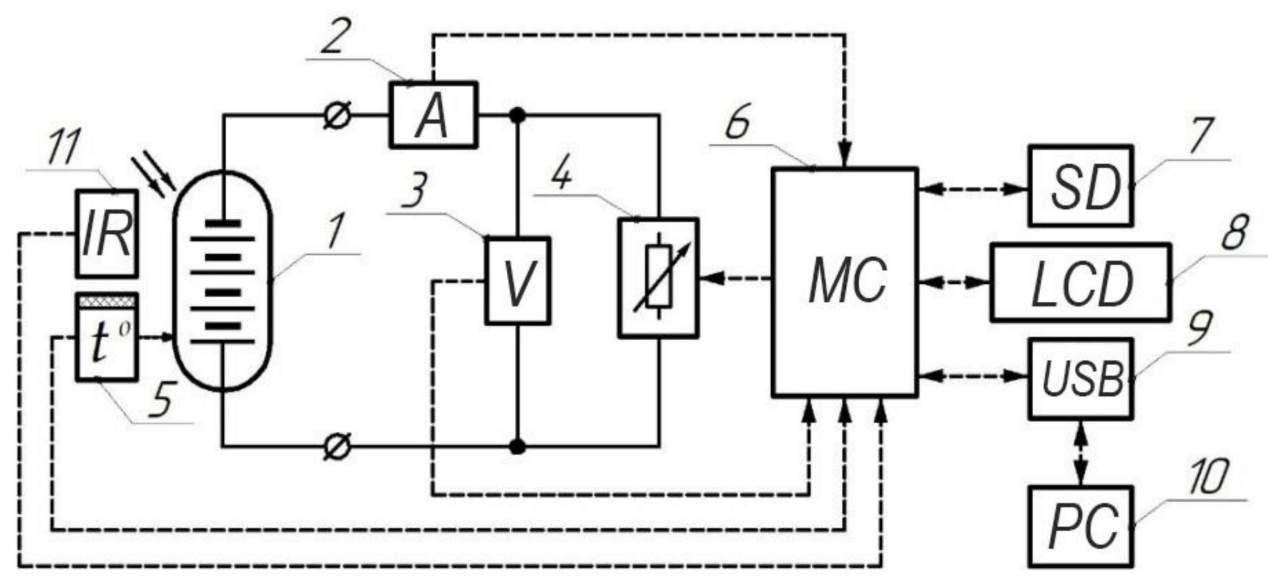

Figure 1. Block diagram of the information-measuring complex (1-PV module; 2 - current sensor; 3-voltage sensor; 4-special adjustable load; 5-solar cell and environment temperature sensor; 6-microcontroller; 7-electronic storage; 9-interface microcontroller; 10 - personal computer; 11 light sensor).

An integrated sensor Allegro ACS712 is used for current measurement. The voltage is measured using a resistive voltage divider. A digital pyrometric sensor MLX90615 is used to measure the temperature. The advantages of this sensor are high measurement accuracy (up to $0.5{ }^{\circ} \mathrm{C}$ ) at a resolution of $0.02{ }^{\circ} \mathrm{C}$, factory calibration, and a convenient SMBus connection interface. To exclude the influence of illumination on the sensor readings, the housing contains an optical filter with a passband of $5.5 \ldots 14 \mu \mathrm{m}$. The digital light sensor MAX44009 is used as the light sensor. Illumination parameters are measured by means of a digital sensor MAX44009. The advantages of using it are factory calibration and a wide 
range of illumination level measurements from 0.045 to 188,000 lux with a resolution of 22 bits.

\section{Efficiency Estimation of PV Installation}

\subsection{PV Installation with Shunt Diodes}

The use of shunt diodes eliminates the influence of shaded modules on the power generation of other (unshaded) modules located in the same series circuit. Without their use, the current of the entire array of series-connected modules does not exceed the current of the least illuminated photocell [25]. This causes energy dissipation on the shaded element (the so-called "hot spot effect") with subsequent damage [26,27]. In this regard, the bypass diodes also perform the protective function of the module, protecting it from damage [28-30].

Shunt diodes are located directly on the output terminals of the modules. They are connected in such a way that they conduct current in the forward direction $\left(\mathrm{I}_{\mathrm{sh} 1}, \mathrm{I}_{\mathrm{sh} 2}\right)$ when reverse bias voltage $\left(U_{b 1}, U_{b 2}\right)$ is applied to shaded panels (Figure 2). Reverse bias voltage occurs if the current flowing in the serial chain I creates a voltage drop in the shaded area greater than the voltage generated by the group of shaded panels themselves. In this case, the only loss is the power dissipated in the diodes themselves, due to the voltage drop across them.

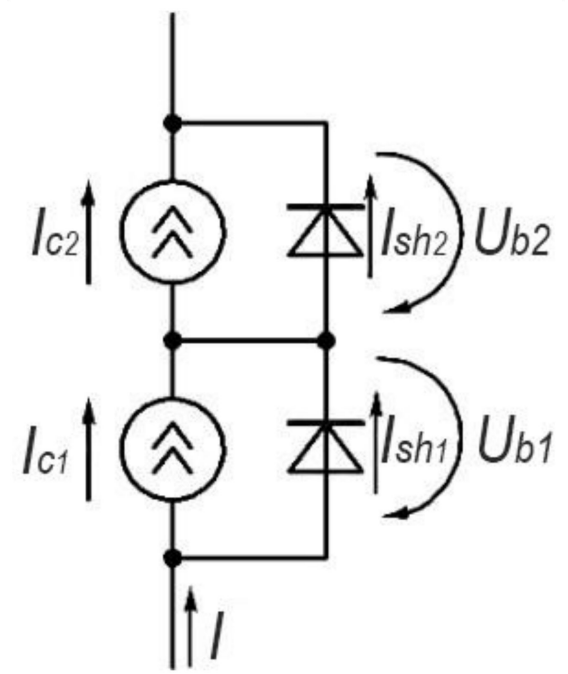

Figure 2. Switching on shunt diodes with PV modules.

Due to the fact that shunt diodes, when uneven illumination occurs, disconnect (shunt) a group of solar cells that has come under a reverse bias voltage (shaded group) that is not able to provide a load current, the current-voltage characteristic of a PV installation is formed by individual characteristics of each such group (Figure 3).

When shunting groups of solar cells with diodes, it is necessary to take into account the voltage drop across them, which is determined by the ratio:

$$
U_{d}=\sum_{i=1}^{p} U_{d i}
$$

where $p$ is the number of solar cell groups shunted by diodes; $U_{d}$ is the shunt diode voltage drop $(\mathrm{V})$.

The number of solar cell groups shunted by diodes can be calculated from the ratio:

$$
p=\frac{n_{m}-n_{x}}{z}
$$


where $n_{m}$ is the total number of solar cells in the array; $n_{x}$ is the number of solar cells in a group not shunted by a diode; $z$ is the number of solar cells per shunt diode.

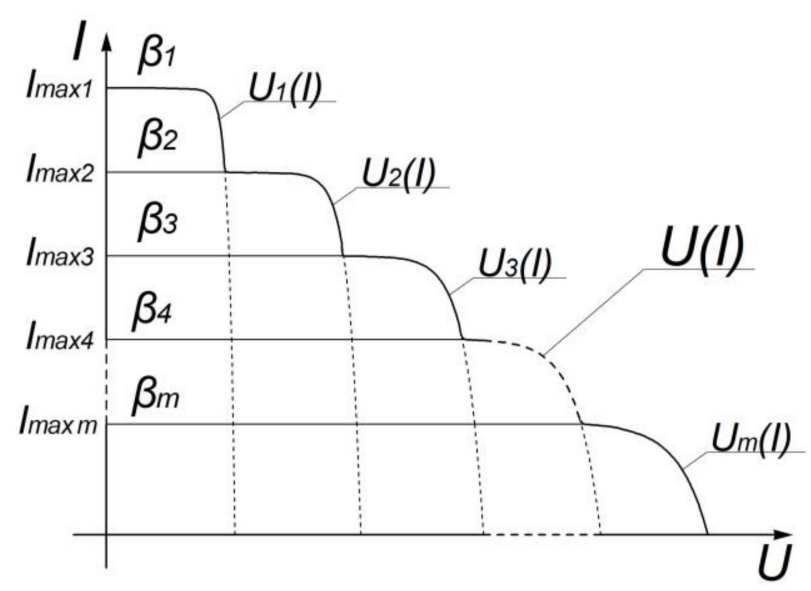

(a)

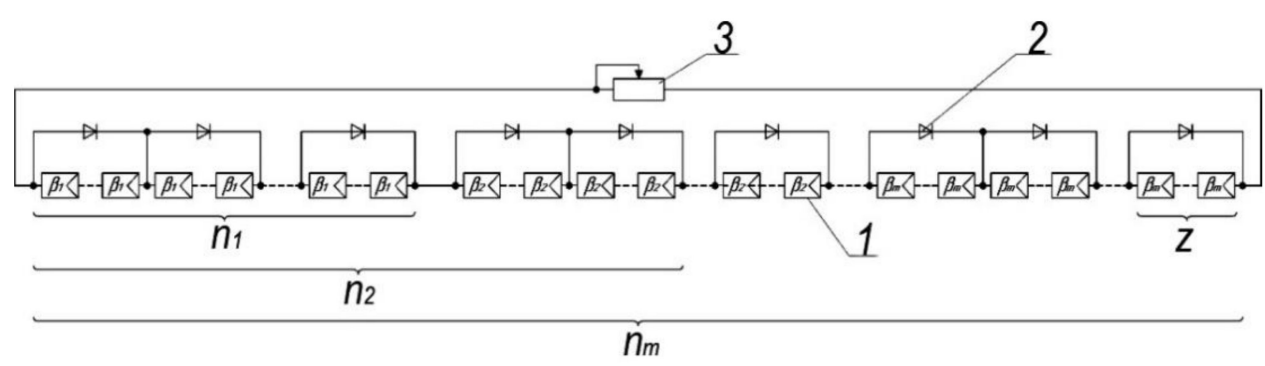

(b)

Figure 3. Current-voltage characteristic of an unevenly illuminated array of solar cells (a) and its structural diagram (b) (1—solar cell; 2-shunt diode; 3-load).

Thus, the current-voltage characteristic $\mathrm{U}(\mathrm{I})$ of such an array can be described by the following system of equations:

$$
\left\{\begin{array}{c}
U_{1}(I)=\sum_{i=1}^{n_{1}} U_{i}(I)-U_{d} p=\frac{n_{1}(\mathrm{~A} k T)}{q} \ln \left(\frac{I_{p h 1}}{I_{0}}-\frac{I}{I_{0}}+1\right)-n_{1} I R_{s}-U_{d}\left(\frac{n_{m}-n_{1}}{z}\right), \text { at } I>I_{\max 2} \\
U_{2}(I)=\sum_{i=1}^{n_{2}} U_{i}(I)-U_{d} p=\frac{n_{2}(\mathrm{~A} k T)}{q} \ln \left(\frac{I_{p h 2}}{I_{0}}-\frac{I}{I_{0}}+1\right)-n_{2} I R_{s}-U_{d}\left(\frac{n_{m}-n_{2}}{z}\right), \text { at } I_{\max 2} \geq I>I_{\max 3} \\
\ldots \ldots \cdots \\
U_{m}(I)=\sum_{i=1}^{n_{m}} U_{i}(I)=\frac{n_{m}(\mathrm{~A} k T)}{q} \ln \left(\frac{I_{p h m}}{I_{0}}-\frac{I}{I_{0}}+1\right)-n_{m} I R_{s}, \text { at } I \leq I_{\max m}
\end{array}\right.
$$

where $m$ is the number of groups with elements with different lighting; $n_{1}, n_{2}, \ldots, n_{m}$ are the number of elements in the corresponding group; $I_{\max 1}, I_{\max 2}, \ldots, I_{\max m}$ are the maximum current of the corresponding group, (A); $I_{p h 1}, I_{p h 2}, \ldots, I_{p h m}$ are the photocurrent of the group with the corresponding value of the intensity of solar radiation $\beta_{1}, \beta_{2}, \ldots$, $\beta_{m},(\mathrm{~A})$.

Obviously, the characteristic of each group of solar cells in such an installation has its own point of maximum power (MPP), which is the point of local maximum (LMP) general characteristics $\mathrm{U}(\mathrm{I})$. Wherein, that with the greatest power is the global extremum, or the point of the absolute maximum (AMP), determining the maximum power take-off from PV 
installations. MPP on the power characteristic of the solar cell array $\mathrm{P}(\mathrm{U})$ will be defined as the extremum of the curve $S_{p}(U)$ drawn along the points LMP shown in Figure 4.

$$
P_{A M P}=\frac{d S_{p}(U)}{d U}=0
$$

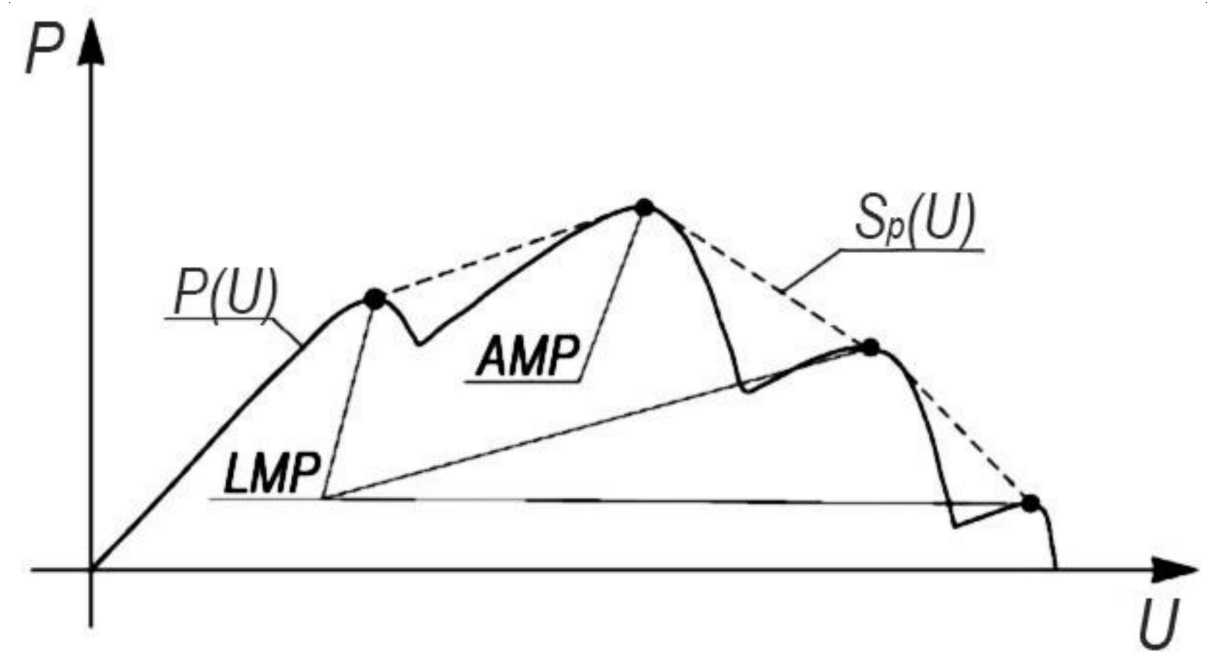

Figure 4. Power characteristic of an unevenly illuminated array of solar cells.

It can be seen from the figure that MPP can fall on the characteristic of any group of solar cells included in the array, depending on the radiation intensity in the shaded areas and the number of shaded elements. It follows from this that most of the algorithms for determining MPP (disturbance and observation, constant voltage (current), augmented conductivity, and others) are not able to determine the AMP in such conditions, setting the mode of electrical energy extraction located near, or the corresponding LMP, which leads to significant electrical energy losses-algorithmic losses equal to:

$$
P_{\text {loss }}^{A}=P_{A M P}-P_{L M P},
$$

where $P_{A M P}$ is the power at the point of absolute maximum (W); $P_{L M P}$ is the local maximum power $(\mathrm{W})$.

The total losses of the PV array, in this case, will be equal to:

$$
P_{\text {loss }}=P_{\text {sh }}+P_{\text {loss }}^{A}+P_{d}=P_{s h}+P_{A M P}-P_{L M P}+P_{d},
$$

where $P_{s h}$ is the power of a group of solar cells, switched off by shunt diodes, under uniform illumination, given by the Equation $(7),(\mathrm{W}) ; P_{d}$ is the power dissipated by the shunt diodes, given by the Equation (11), (W).

$$
\begin{gathered}
P_{s h}=I U_{s h}=I\left[\frac{\left(n_{m}-n_{x}\right)(\mathrm{A} k T)}{q} \ln \left(\frac{I_{p h}}{I_{0}}-\frac{I}{I_{0}}+1\right)-\left(n_{m}-n_{x}\right) I R_{s}\right], \\
P_{d}=I U_{d} p=I U_{d}\left(\frac{n_{m}-n_{1}}{z}\right) .
\end{gathered}
$$

If the MPPT is correctly determined by the controller of the maximum power point, the losses will be equal to:

$$
P_{\text {loss }}=P_{s h}+P_{d}
$$

It should also be noted that the shunting of partially shaded PV modules with diodes can lead to an even more significant limitation of the power generation of a PV installation. The reason for this is that the input voltage range of the inverter may be higher than the voltage range near the point of maximum power of the PV installation, as a result of which 
the energy extraction from them will be carried out in a sub-optimal mode or not at all due to the impossibility of turning on the inverter.

Based on this, it can be summarized that the use of shunt diodes is a prerequisite for the reliable operation of PV installations, but they are not able to solve all the problems that arise in conditions of uneven illumination. Such problems include:

- shutdown of a sufficiently large group of solar cells (having partial or complete shading), despite the fact that they are almost always still capable of generating electrical energy;

- decreasing the voltage at the point of maximum power of the entire array of solar cells, which leads to a significant decrease in its energy efficiency when arrays are connected in parallel or when using an inverter with an input voltage range value exceeding this value.

\subsection{PV Installation with Individual Matching Converters and Micro-Inverters}

In order to solve the first and partly the second problem, recently, individual matching converters and micro-inverters installed on each (in some cases up to two) PV module have begun to be widely used [31-34]. These devices set the selection of electrical energy to the point of maximum power for each module individually, which allows you to receive more energy from solar installations operating in uneven lighting conditions. Their use makes it possible to install modules on almost any plane or site, making the most of the entire available area. The advantages of such devices can also be attributed to the fact that most of them have a remote monitoring function, which allows you to monitor the performance of each module, as well as to analyze the main electrical parameters.

The outputs of individual matching converters are connected in a series (Figure 5a), which makes it possible to easily implement them in already built solar power plants. Switching of micro-inverters is carried out by means of their parallel connection (Figure $5 b$ ), which complicates their implementation at the constructed stations.

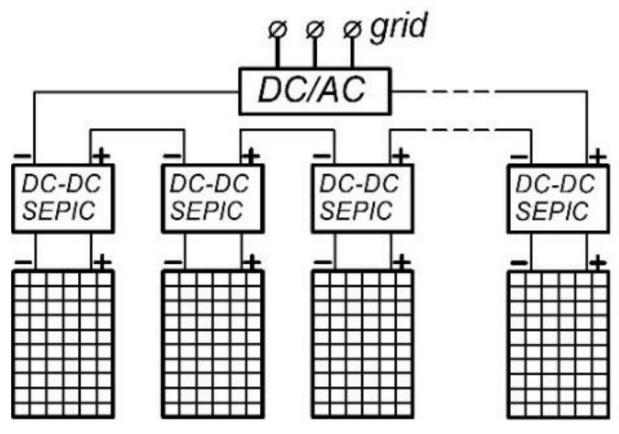

(a)

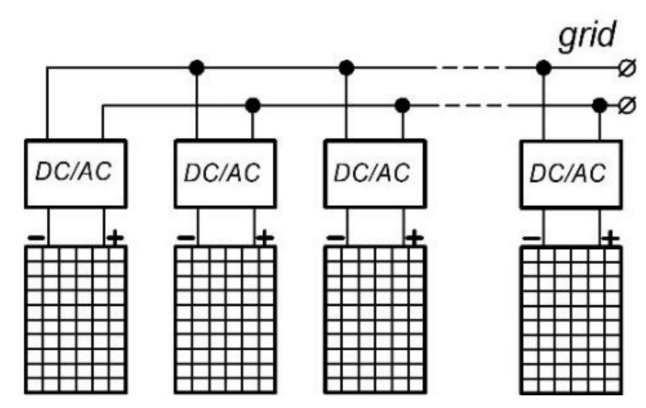

(b)

Figure 5. Switching of individual matching converters (a) and micro-inverters (b).

The world leader in the production and implementation of individual matching converters (IMC) is the company "Tigo Energy." The principle of their operation is based on the use of DC/DC SEPIC converters with an automatic control system that sets the mode of taking electrical energy from the module at the maximum power point, with a current value equal to the current of the entire battery at the maximum power point. This means that in the event of shadowing of one of the modules, the converter reduces the value of the output voltage, increasing the output current. Thus, the module is not switched off by shunt diodes, and it continues to generate electrical energy, albeit at a reduced power in comparison with other series-connected non-shaded modules. As a result, $P_{d}$ is excluded from the calculation of losses, and $P_{s h}$ is reduced by the amount of power $P_{I M C}$. Thus, the power loss of a PV installation will be equal to:

$$
P_{\text {loss }}=P_{\text {sh }}-P_{I M C} \text {. }
$$


Power $P_{I M C}$ will be equal to:

$$
P_{I M C}=I \sum_{i=1}^{p} U_{I M C}
$$

where $U_{I M C}$ is the voltage at the output of an individual matching converter, $(\mathrm{V})$, equal to:

$$
U_{I M C}=\frac{U_{I M C}^{i n} I_{I M C}^{i n}}{I} \eta_{I M C}
$$

where $U_{I M C}^{i n}$ is the voltage at the input of an individual matching converter $(\mathrm{V}) ; I_{I M C}^{i n}$ is the input current of the individual matching converter (A); $\eta_{I M C}$ is the efficiency of an individual matching converter.

From relations (14) and (15) it follows that for any values of the current $I$ array, the output power of the individual matching converter is constant, which is confirmed by its output current-voltage characteristic $U_{I M C}(I)$, shown in Figure 6:

$$
P_{I M C}=\sum_{i}^{p}\left(U_{I M C}^{i n} I_{I M C}^{i n} \eta_{I M C}\right)_{i}=I \cdot \sum_{i=1}^{p} U_{I M C} i=\text { const. }
$$

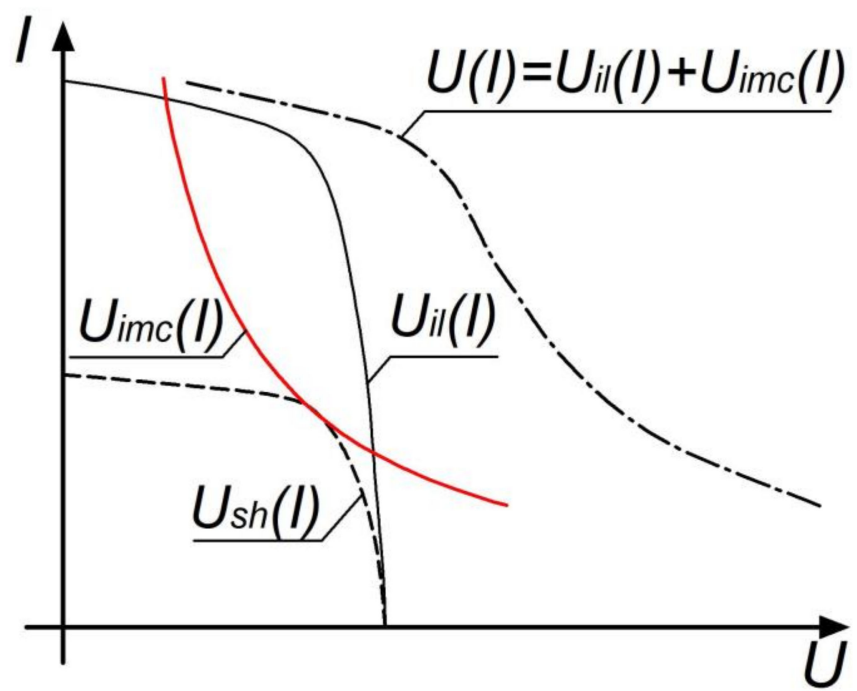

Figure 6. Current-voltage characteristic of a group of solar cells using an individual matching converter.

From the characteristics, it is seen that the current $(I)$ can take values both above and below the current value at the point of maximum power of the characteristic of a group of solar cells connected to the input of an individual matching converter. Thus, at any value of the array current, the current at the output of the individual matching converter $\left(I_{I M C}\right)$ is able to take on the same meaning $I=I_{I M C}$. Hence, when the solar cells group with such a converter, it is capable of transmitting electrical energy under any illumination, whether it be shading, pollution, or increased illumination (for example, when working in conjunction with solar concentrators).

The operating point of a PV installation with an individual matching converter and the value of the partial shading loss can be calculated from the system: 


$$
\left\{\begin{array}{c}
P_{\text {loss }}=P-\left(P_{s h}-P_{I M C}\right) \\
P_{I M C}=\sum_{i}^{p}\left(U_{I M C}^{i n} I_{I M C}^{i n} \eta_{I M C}\right)_{i}=I \sum_{i=1}^{p} U_{I M C} ; \\
U_{I M C}=\frac{U_{I M C}^{i n} I_{I M C}^{i n}}{I} \eta_{I M C} ; \\
I_{I M C}^{i n}=I_{p h}-I_{0}\left[\exp \left(\frac{q\left(U_{I M C}^{i n}+I_{I M C}^{i n} R_{s}\right.}{n_{i n}(\mathrm{AkT})}\right)-1\right] \\
\frac{q\left(U_{I M C}^{i n}+I_{I M C}^{i n} R_{s}\right)}{n_{i n}(\mathrm{AkT})}-\ln \left[\frac{I_{p h}-I_{0}}{I_{0}\left(1+\frac{q\left(U_{I M C}^{i n}+I_{I M C}^{i n} R_{s}\right.}{n_{i n}(\mathrm{AkT})}\right)}\right]=0 \\
I_{p h}=\left[I_{s c(s t c)}+K_{i}\left(T-T_{s t c}\right)\right] \frac{\beta_{i n}}{\beta_{s t c}}
\end{array}\right.
$$

where $n_{\text {in }}$ is the number of solar cells at the input of an individual matching converter; $\beta_{\text {in }}$ is the intensity of solar radiation, the least illuminated solar cell at the input of an individual matching converter $\left(\mathrm{W} / \mathrm{m}^{2}\right) ; I=I_{I M C}$, the current in the solar cell array and at the output of the individual matching converter $(\mathrm{A}) ; K_{i}$ is the temperature coefficient of the short-circuit current of the solar cell (A/K); $T_{s t c}$ is the temperature under standard conditions $(298 \mathrm{~K})$; $I_{s c(s t c)}$ is the short-circuit current of the solar cell under standard conditions (A).

If a group of solar cells in an array that has uneven illumination transmits electrical energy through individual matching converters, and the rest of the normally illuminated group does not have such, then the characteristic of such an array will be formed by the sum of the characteristics of each group with respect to voltage:

$$
U(I)=U_{i l}(I)+U_{I M C}(I),
$$

where $U_{i l}(I)$ is the characteristic of a normally illuminated solar cell array; $U_{I M C}(I)$ is the characteristic of an individual matching converter.

Figure 6 shows the characteristic of such an array for the case of when a group of solar cells with installed individual matching converters $U_{I M C}(I)$ has shading.

Due to the fact that an individual matching converter selects electrical energy at the point of maximum power from the group of solar cells connected to its input, at different output current values the point of maximum power of the array will be determined by the current value at the point of maximum power of the entire PV installation that transmits energy without using converters $\left(I_{(m p p)}=I_{I M C}=I_{i l(m p p)}\right)$. Hence, it follows that the operating mode of such an installation can be described by the system of equations:

$$
\left\{\begin{array}{c}
P_{(M P P)}=I_{(M P P)} U_{(M P P)} ; \\
I_{(M P P)}=I_{p h}-I_{0}\left[\exp \left(\frac{q\left(U_{(M P P)}+I_{(M P P)} R_{s}\right)}{\left(n-n_{i n}\right)(\mathrm{A} k T)}\right)-1\right] \\
U_{(M P P)}=U_{i l(M P P)}+U_{I M C} ; \\
\frac{q\left(U_{i l(M P P)}+I R_{s}\right)}{\left(n-n_{i n}\right)(\mathrm{A} k T)}-\ln \left[\frac{I_{p h}-I_{0}}{I_{0}\left(1+\frac{q\left(U_{i l(M P P)}+I R_{s}\right)}{\left(n-n_{i n}\right)(\mathrm{A} k T)}\right)}\right]=0 \\
U_{I M C}=\frac{U_{I M C}^{i n} I_{I M C}^{i n}}{I_{(M P P}} \eta_{I M C} ; \\
I_{I M C}^{i n}=I_{p h}-I_{0}\left[\exp \left(\frac{q\left(U_{I M C}^{i n}+I_{I M C} R_{s}\right)}{n_{i n}(\mathrm{~A} k T)}\right)-1\right]
\end{array}\right.
$$

Figure 7 shows the electrical characteristics obtained using a mathematical model and as a result of an experiment in which two KV-260M PV modules and Tigo "Module Maximizer" commercially available matching converters were used. 


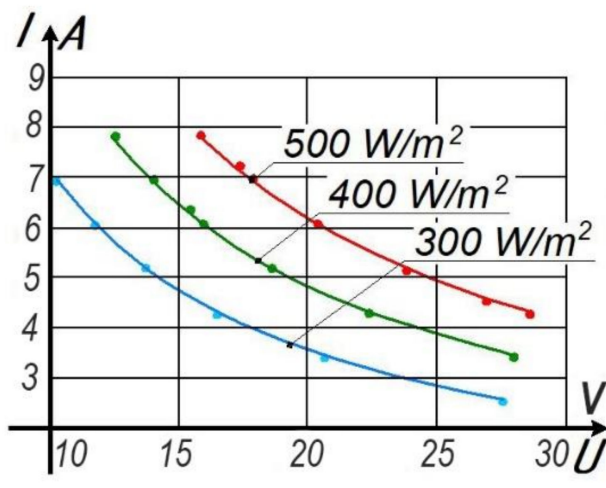

(a)

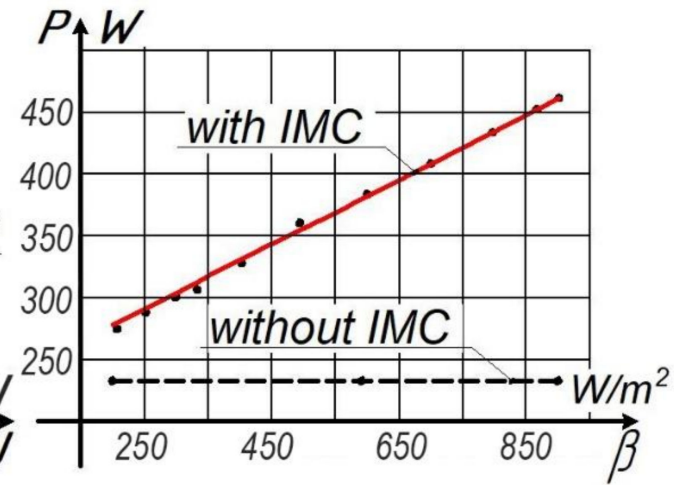

(b)

Figure 7. Results of modeling the operation of a solar cell array with individual matching converters, (a) - volt-ampere characteristics of the matching converter at different values of the radiation intensity; (b)-dependence of the array output power on the radiation intensity of one of the modules (dots show the results of experimental measurements).

The main disadvantages of individual matching converters are:

- a significant increase in the cost of the installation (the cost of the ICP is about $15-20 \%$ of the cost of the module);

- reduction of the voltage value of the entire array of PV modules at the point of maximum power, which, as in the case of shunt diodes, significantly affects the energy efficiency during parallel switching of arrays.

The introduction of micro-inverters in the photovoltaic industry is considered one of the largest technological advances in the industry today [34]. Manufacturers guarantee an increase in the power generation of solar installations by $5-25 \%$ due to their use [35]. The leader in the implementation and promotion of these devices is the American company Enphase Energy, which created the first successful commercial micro-inverter. At present, many companies have appreciated the advantages of this development, as a result of which they began to independently develop and produce micro-inverters [36-38].

The principle of operation of a micro-inverter is similar to a central inverter; the main difference is only the power. The positive effect of micro-inverters is achieved due to the fact that, such as ICPs, they optimize the operation of each module separately, allowing them to work at the maximum power point under any conditions. The absence of a central inverter also has a positive effect on the reliability of the installation and makes it more flexible in the possibilities of subsequent expansion, simplifies installation work, and increases the service life due to the absence of active cooling systems.

Despite all the advantages of using micro-inverters, they have a number of disadvantages, and the main ones are:

1. High cost. The use of micro-inverters instead of the central one in industrial power plants is on average $50-85 \%$ more expensive.

Reduced energy efficiency with uniform illumination of solar cells. This is due to the fact that the efficiency of micro-inverters is less than that of the central one by an average of $2.5-4 \%$, as well as the fact that the voltage in the connecting wires has lower voltage values.

2. Lack of possibility of implementation in existing power plants with a central inverter to solve the problem of uneven illumination.

\subsection{PV Installation with Reconfigurable Switching Systems}

Another way to increase the energy efficiency of solar installations operating in conditions of uneven illumination is the use of reconfigurable switching systems. This method has not yet received practical implementation in industrial solar power plants. 
However, at present, scientists and researchers from many countries are actively working in this direction $[39,40]$.

The principle operation of reconfigurable switching systems is that by using a switching matrix, such switching is performed, in which shaded modules located in different arrays are included in one array, and their places are replaced by normally illuminated modules (Figure 8).

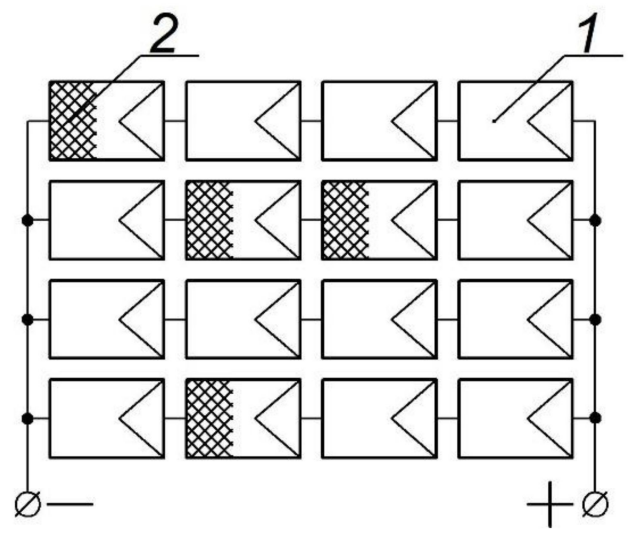

(a)

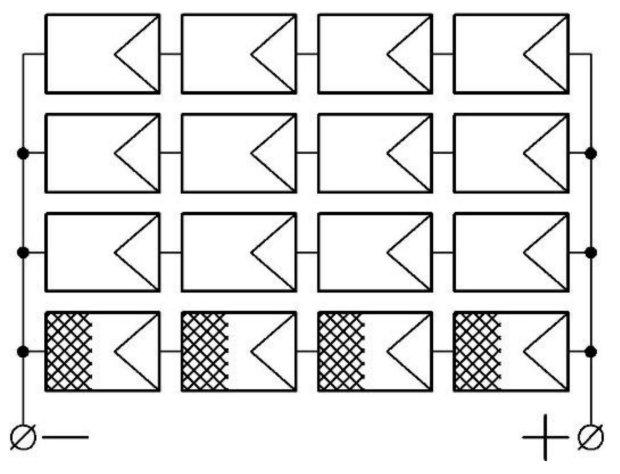

(b)

Figure 8. The operating principle of reconfigurable switching systems; (a)—solar modules before commutation; (b)—reconnected modules (1—normally lit module; 2—shaded module).

The use of this method makes it possible to partially solve both the problem of disconnecting the shaded modules by shunt diodes and the problem of voltage mismatch in parallel connected arrays of modules operating in conditions of uneven illumination. In this case, the disadvantages of the method are:

- practical complexity of the method implementation in industrial solar power plants;

- $\quad$ high cost, justified by the use of expensive switching matrices and a large number of connecting wires designed for a current of at least $10 \mathrm{~A}$;

- inefficiency with a small number of shaded solar modules.

\subsection{PV Installation with Differentiated Maximum Power Take-Off Systems}

The voltage matching of parallel arrays of modules also allows for the use of differentiated maximum power take-off systems, the block diagram of which is shown in Figure 9 [41]. The principle of operation of such systems is that parallel arrays of modules transmit electrical energy through active voltage stabilizers, which set their output voltage to the same nominal value. At the same time, the converters search for the maximum power point (MPP) and optimize it. This allows for the maximum extraction of electrical energy from each array at their different illumination, temperature, or the use of PV panels in arrays with different characteristics.

The main disadvantages of using such systems are:

- $\quad$ high cost and material consumption due to the fact that the stabilizers used are designed for power with a value not lower than the nominal power of the array of modules in which they are installed;

- $\quad$ decrease in energy efficiency due to the fact that, for voltage matching, all the energy generated by the array is converted. Thus, the output power is reduced by the amount of efficiency of the stabilizers. 


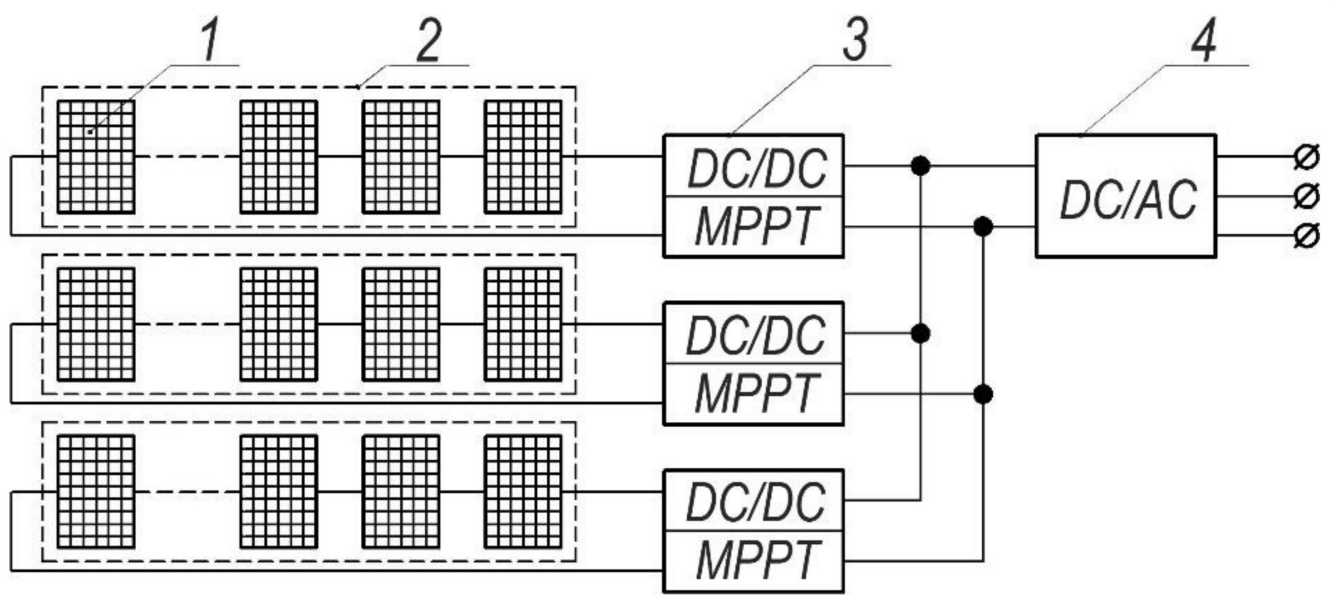

Figure 9. Block diagram of differentiated maximum power take-off systems (1-module; 2 -array of modules; 3-voltage stabilizers with MPPT; 4-inverter).

The analysis shows that, at present, there are quite a large number of technical solutions that make it possible to partially neutralize the influence of uneven illumination on the power generation of PV modules. Moreover, each of them has its own characteristics that limit their widespread use in solar power plants, which have a wide variety of design solutions, including various options for support structures, solar cell switching, orientation systems, the nature of illumination, etc.

It should also be noted that some of the methods initially do not seem promising for implementation at industrial power plants due to the practical complexity of their implementation, high cost, or the impossibility of incorporation into existing plants. Such methods include those that allow solving the problem of voltage matching of arrays of PV modules in parallel switching, reconfigurable switching systems, microinverters, and differentiated maximum power take-off systems. As a result, one of the urgent tasks is to create an economically viable method that allows the selection of electrical energy from parallel groups of PV modules (mixed switching) at the points of maximum power operating in shading conditions.

\subsection{Proposed Method of Matching PV Modules with Mixed Commutation under Partial Shading}

To solve the problem of matching parallel-connected arrays of PV modules, the authors have developed a method that automatically regulates the output voltages of the arrays at the points of maximum power. The essence of the method is illustrated in Figure 10 and consists of the fact that to take the maximum power from the arrays of PV modules (1), the arrays are matched by including an additional power element (APE) (2) in each of them (which needs to be matched). The voltage of each additional power element is regulated using a microcontroller device (5), to a value at which the total power of the PV installation will be maximum. Electric energy is supplied to the additional battery from the same PV batteries, providing galvanic isolation, or from any other source of electrical energy. At the same time, the maximum power point of the PV arrays are monitored and optimized using the maximum power take-off device (3). After that, electrical energy is transmitted directly to the load (4), or through a converter, or is accumulated. 


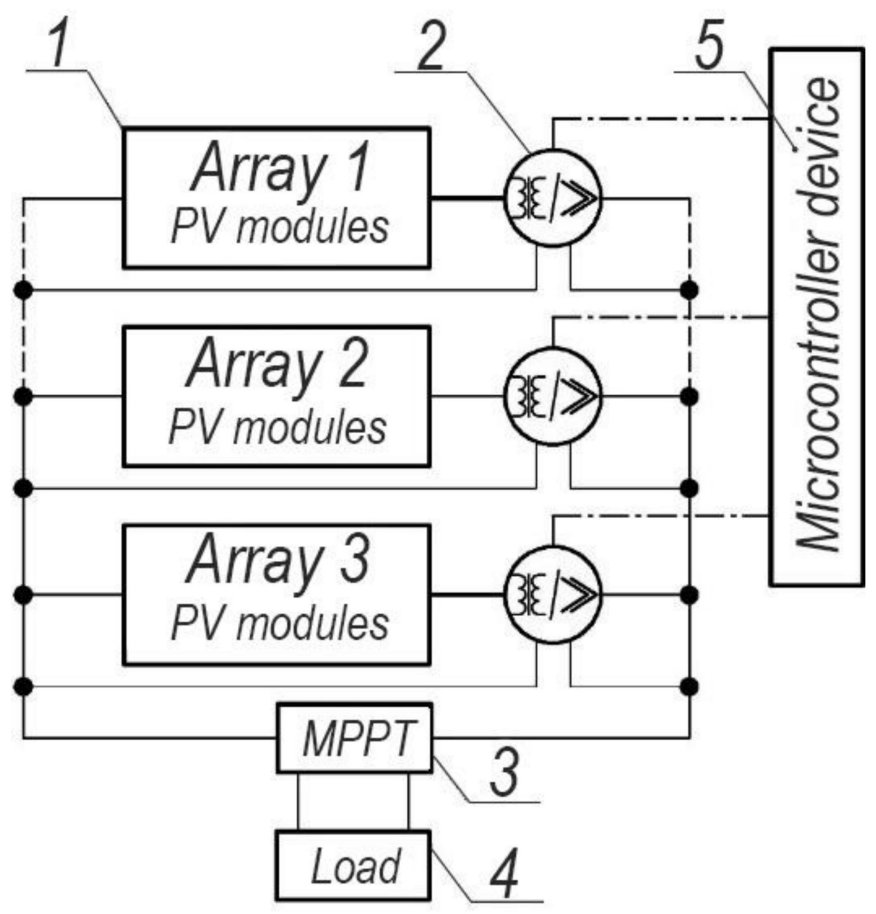

Figure 10. Block diagram of a method for taking maximum power from arrays of PV modules.

The use of this method allows for the selection of electrical energy from the mismatched array of photoelectric converters in the MPP. This is due to the fact that the load at the output of such an array corresponds to the MPP. In this case, the voltage at its output is equal to the voltage of other parallel arrays. Thus, the use of additional, automatically regulated power elements allows you to set the mode for the selection of electrical energy from the mismatched array of the ESS in the MPP with an output voltage equal to the voltage of other parallel connected arrays. In this case, the power loss of the battery can be calculated from the system of equations:

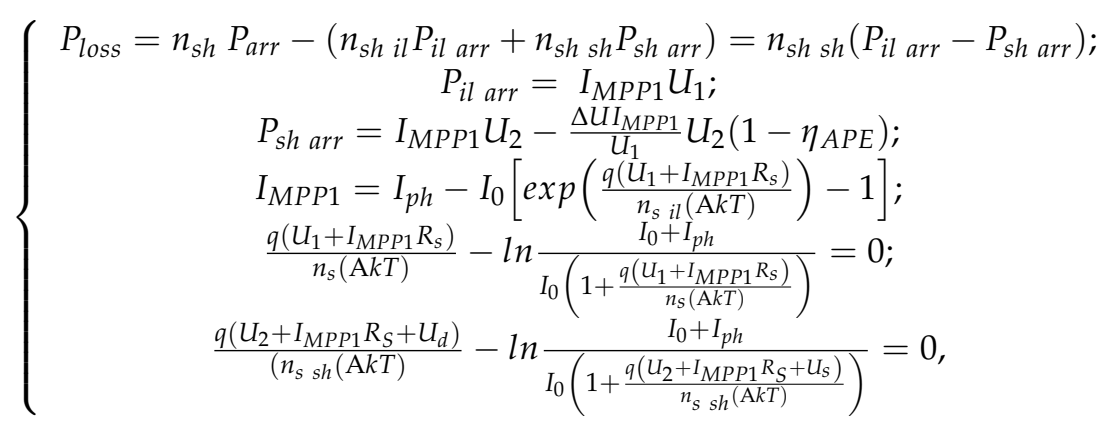

where $\eta_{A P E}$ is the efficiency of an additional power element.

\section{Discussion}

Figure 11 shows the summary graph of power losses of a PV battery consisting of parallel-connected arrays of solar cells formed from 10 series-connected PS-250 PV modules with partial sequential shading of modules of one of the arrays, obtained as a result of mathematical modeling. Figure 12 shows the conducted experimental work on APE prototype estimation on the Sevastopol solar plant. 


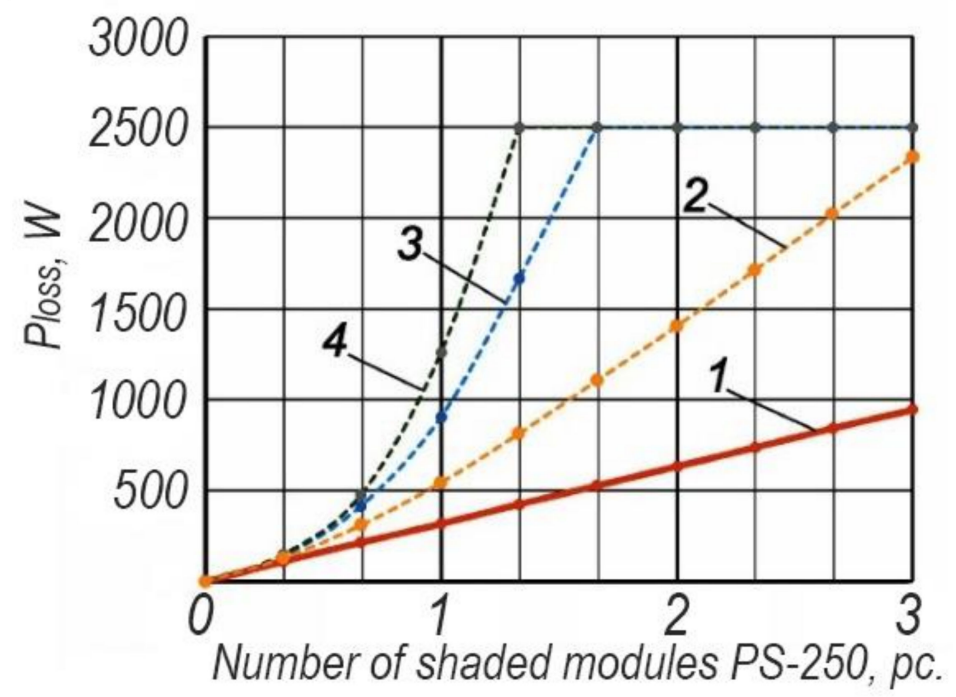

Figure 11. Graph of the dependence of the power losses of a PV battery on the partial shading of PV modules of one of the solar cell arrays (1-with APE; 2-consisting of three arrays of solar cells and installation of MPPT in AMP; 3-consisting of 10 arrays of solar cells and the installation of MPPT in AMP; 4-installing MPPT in LMP).

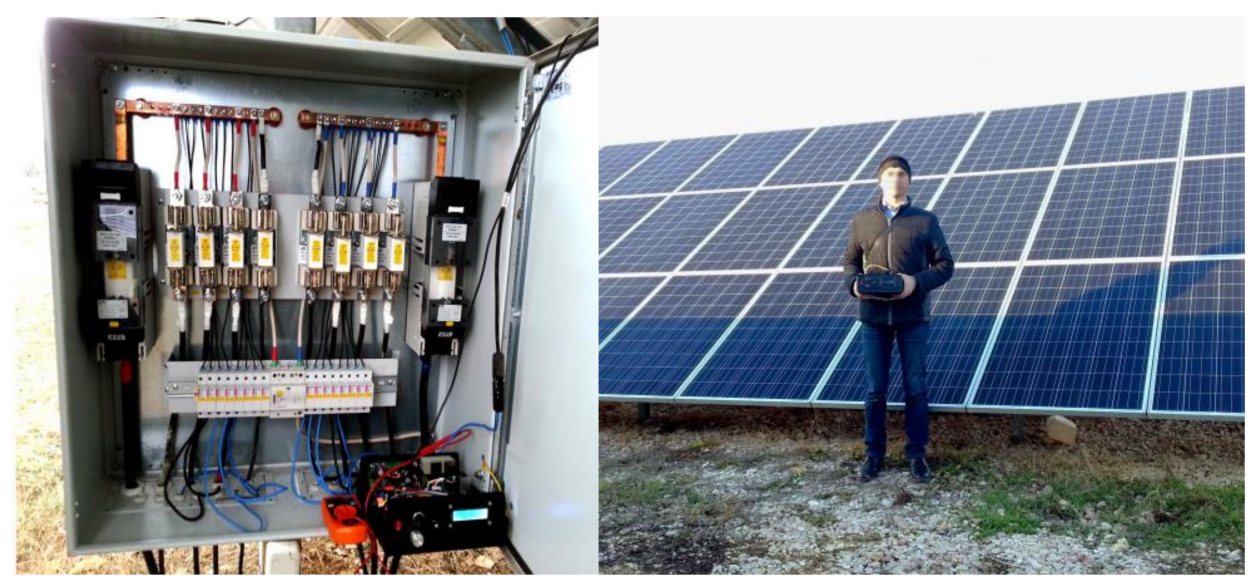

Figure 12. The conducted experimental work on APE prototype estimation on the Sevastopol solar plant.

It can be seen from the graph that the installation of additional power cells significantly reduces the energy losses of the PV battery with partial shading of solar cells, which significantly increases the energy output of the battery operating in such conditions. A particularly significant effect from the use of this method is achieved when it is used in solar PV installations consisting of a large number of parallel arrays of solar cells, or when using MPPT with search algorithms for MPP that establish the mode of taking electrical energy outside the AMP. In such cases, partial shading of more than one panel in a parallel group consisting of ten panels practically does not allow the generation of electrical energy of such a group without voltage matching with other parallel groups.

The obtained estimates of the effectiveness of various methods for increasing the output power of a partially shaded array of PV modules are shown in Table 2. 
Table 2. Output power of the PV array using different methods.

\begin{tabular}{ccccc}
\hline $\begin{array}{c}\text { Number of Shaded } \\
\text { Modules in the Array }\end{array}$ & $\begin{array}{c}\text { Output Power of the PV } \\
\text { Array Using APE Method } \\
\text { (W) }\end{array}$ & $\begin{array}{c}\text { Output Power of the PV } \\
\text { Array Using IMC } \\
\text { Method (W) }\end{array}$ & $\begin{array}{c}\text { Output Power of the PV } \\
\text { Array Using the Method } \\
\text { "Differentiated } \\
\text { Maximum Power } \\
\text { Take-Off Systems" (W) }\end{array}$ & $\begin{array}{c}\text { Output Power of the PV } \\
\text { Array without } \\
\text { Additional Methods (W) }\end{array}$ \\
\hline 0 & 2500 & 2500 & 2500 & 2500 \\
1 & 2230 & 1970 & 2050 & 1650 \\
3 & 1850 & 1100 & 1790 & 100 \\
\hline
\end{tabular}

The presented results demonstrate the effectiveness of the proposed method (APE) based on voltage matching of parallel-connected arrays.

\section{Conclusions}

The existing methods for the selection of electrical energy from solar PV installations operating in conditions of partial shading, consisting of the use of shunt diodes, individual matching converters, micro-inverters, reconfigurable switching systems, and differentiated maximum power take-off systems, in some cases are not effective or economically justified solutions. Shunt diodes disconnect (shunt) solar cell groups that are partially shaded and lead to voltage mismatch at the maximum power point of parallel PV arrays. IMC add significantly to installation costs and lead to voltage mismatches in parallel arrays of modules. Micro-inverters significantly increase the cost of installations, reduce their efficiency in conditions of uniform illumination, and cannot be used in existing stations with a central inverter. Reconfigurable switch systems are expensive and inefficient with a small number of shaded solar modules. Differentiated maximum power take-offs are also costly, energy inefficient solutions.

To increase the energy efficiency of PV installations with mixed switching of PV modules, it is proposed to use a method consisting of voltage matching at the points of maximum power of parallel arrays of modules by sequentially including an APE with variable electrical characteristics. The value of the output voltage APE is set by the microcontroller device. The value of this voltage is equal to the value of the voltage mismatch of the parallel-connected arrays of PV modules. Electric energy is supplied to the APE from the same arrays of PV modules, through a device providing galvanic isolation or from any other source of electrical energy. An important feature of this method is that, to match the modules, it is not required to convert all the electrical energy they generate, but only a small part of it, determined by the level of mismatch.

Comparative results of calculating the energy losses of a PV installation formed of 10 parallel-connected groups of PV modules show that, with partial shading of one of ten modules, the proposed method can increase the energy efficiency of an array with a shaded module by $30 \%$ when the MPPT is installed by the AMP controller and by $40 \%$ in LMP. At the same time, in the case of partial shading of two or more modules, the shaded array without matching devices practically does not generate electrical energy.

We suppose that the partial shading (including the low-intensity light of artificial indoor light sources) will also have a negative impact on the efficiency of batteries with organic photovoltaics cells, described in [21,42]. The degree of influence of partial shading on the efficiency of such a battery will depend on the type of connection of the cells (serial, parallel, or mixed) and the type of the partial shading (uniform or uneven). In addition, the efficiency of such a PV battery will be significantly influenced by the presence of shunt diodes and the method of taking electrical energy that is used. The models presented in the article allow the calculation of energy losses due to partial shading of batteries with organic photovoltaics cells. However, for the case of organic photovoltaics elements, it is necessary to obtain specific values of parameters and coefficients (ideality factor, internal resistances, photocurrent, temperature coefficients, etc.), but it is a separate interesting actual research problem. 
The proposed method for increasing the energy efficiency of PV installations operating in conditions of partial shading has extreme practical importance for solving the problems of smart urban environment development. It allows the minimization of the detrimental effect of existing urban objects (buildings, trees, communications, etc.) on the efficiency of PV installations introduction, which are an excellent alternative to using the existing urban electrical grid, which sometimes requires destructive interference in urban processes and leads to significant financial costs, in some cases exceeding the cost of the installed equipment. In addition, meeting the increased energy needs only through the use of traditional electricity generation will lead to the deterioration of the environmental situation. Thus, the authors see the creation of a methodology for parametric optimization of power plants operating from renewable energy sources that contribute to the sustainable development of the urban environment in the context of digital transformation as an extremely important area of further research.

Author Contributions: Conceptualization, P.K.; formal analysis, V.A.P., L.M.; methodology, L.Y.; supervision, L.Y.; validation, D.V., M.J., A.N.; visualization, V.A.P., P.K., Z.L.; writing-original draft, P.K.; writing-review and editing, D.V., V.B., V.A.P. All authors have read and agreed to the published version of the manuscript.

Funding: This research received no external funding.

Institutional Review Board Statement: Not applicable.

Informed Consent Statement: Not applicable.

Conflicts of Interest: The authors declare no conflict of interest.

\section{References}

1. Kannan, N.; Vakeesan, D. Solar energy for future world: - A review. Renew. Sustain. Energy Rev. 2016, 62, 1092-1105. [CrossRef]

2. Tiwari, G.N.; Tiwari, A. Handbook of Solar Energy; Springer: Singapore, 2016.

3. Kuznetsov, P.N.; Safonov, V.A. Improving the efficiency of the photovoltaic plant. Energy. Secur. Energy Sav. 2016, 3, 26-30.

4. Kuznetsov, P.N.; Yuferev, L.Y. Increasing the efficiency of photovoltaic converters when connected in series. VIESH Bull. 2017, 1, 90-97.

5. Alonso-Garcia, M.C.; Ruiz, J.M.; Chenlo, F. Experimental study of mismatch and shading effects in the I-V charac-teristic of a photovoltaic module. Sol. Energy Mater. Sol. Cells 2006, 90, 329-340. [CrossRef]

6. Teo, J.C.; Tan, R.H.; Mok, V.H.; Ramachandaramurthy, V.K.; Tan, C. Impact of partial shading on the PV charac-teristics and the maximum power of a photovoltaic string. Energies 2018, 11, 1860. [CrossRef]

7. Krishna, G.S.; Moger, T. Reconfiguration strategies for reducing partial shading effects in photovoltaic arrays: State of the art. Sol. Energy 2019, 182, 429-452. [CrossRef]

8. Li, H.; Yang, D.; Su, W.; Lü, J.; Yu, X. An overall distribution particle swarm optimization MPPT algorithm for pho-tovoltaic system under partial shading. IEEE Trans. Ind. Electron. 2018, 66, 265-275. [CrossRef]

9. Chaibi, Y.; Malvoni, M.; Chouder, A.; Boussetta, M.; Salhi, M. Simple and efficient approach to detect and diagnose electrical faults and partial shading in photovoltaic systems. Energy Convers. Manag. 2019, 196, 330-343. [CrossRef]

10. Belhachat, F.; Larbes, C. A review of global maximum power point tracking techniques of photovoltaic system under partial shading conditions. Renew. Sustain. Energy Rev. 2018, 92, 513-553. [CrossRef]

11. Kuznetsov, P.N.; Ali, L.A.; Kuvshinov, V.V.; Issa, H.A.; Mohammed, H.J.; Al-Bairmani, A.G. Investigation of the losses of photovoltaic solar systems during operation under partial shading. J. Appl. Eng. Sci. 2020, 18, 313-320. [CrossRef]

12. Kharchenko, V.; Nikitin, B.; Tikhonov, P.; Panchenko, V.; Vasant, P. Evaluation of the Silicon Solar Cell Parameters. In Proceedings of the International Conference on Intelligent Computing \& Optimization, Pattaya, Thailand, 4-5 October 2018; Springer: Cham, Switzerland, 2018; pp. 328-336.

13. Panchenko, V.; Izmailov, A.; Kharchenko, V.; Lobachevskiy, Y. Photovoltaic Solar Modules of Different Types and Designs for Energy Supply. Int. J. Energy Optim. Eng. 2020, 9, 74-94. [CrossRef]

14. Panchenko, V. Roofing Solar Panels of Planar and Concentrator Designs. Int. J. Energy Optim. Eng. 2020, 9, 20-40. [CrossRef]

15. Sampaio, P.G.V.; González, M.O.A. Photovoltaic solar energy: Conceptual framework. Renew. Sustain. Energy Rev. 2017, 74, 590-601. [CrossRef]

16. Badis, A.; Boujmil, M.H.; Mansouri, M.N. A Comparative Study on Maximum Power Point Tracking Techniques of Photovoltaic Systems. Int. J. Energy Optim. Eng. 2018, 7, 66-85. [CrossRef]

17. Piasecka, I.; Bałdowska-Witos, P.; Piotrowska, K.; Tomporowski, A. Eco-Energetical Life Cycle Assessment of Materials and Components of Photovoltaic Power Plant. Energies 2020, 13, 1385. [CrossRef] 
18. Granata, G.; Pagnanelli, F.; Moscardini, E.; Havlik, T.; Toro, L. Recycling of photovoltaic panels by physical operations. Sol. Energy Mater. Sol. Cells 2014, 123, 239-248. [CrossRef]

19. Rasheed, M.; Alabdali, O.; Shihab, S. A New Technique for Solar Cell Parameters Estimation of The Single-Diode Model. J. Physics Conf. Ser. 2021, 1879, 1742-6596. [CrossRef]

20. Kumari, J.; Babu, C.S. Mathematical Modeling and Simulation of Photovoltaic Cell using Matlab-Simulink Environment. Int. J. Electr. Comput. Eng. 2011, 2, 26-34. [CrossRef]

21. Saeed, M.A.; Kim, S.H.; Kim, H.; Liang, J.; Woo, H.Y.; Kim, T.G.; Yan, H.; Shim, J.W. Indoor Organic Photovoltaics: Optimal Cell Design Principles with Synergistic Parasitic Resistance and Optical Modulation Effect. Adv. Energy Mater. 2021, 11, 27. [CrossRef]

22. Hua, C.; Shen, C. Study of maximum power tracking techniques and control of DC/DC converters for photovoltaic power system. In Proceedings of the 29th Annual IEEE Power Electronics Specialists Conference (Cat. No.98CH36196), Fukuoka, Japan, 22 May 2002; PESC 98 Record. Volume 1, pp. 86-93. [CrossRef]

23. Meyer, E.L. Extraction of Saturation Current and Ideality Factor from Measuring Voc and Isc of Photovoltaic Modules. Int. J. Photoenergy 2017, 2017, 8479487. [CrossRef]

24. Tsai, H.L.; Tu, C.S.; Su, Y.J. Development of generalized photovoltaic model using MATLAB/SIMULINK. In Proceedings of the World Congress on Engineering and Computer Science, San Francisco, CA, USA, 22-24 October 2008; pp. 1-6.

25. Rauschenbach, H.S. Solar Cell Array Design Handbook: The Principles and Technology of Photovoltaic Energy Conversion; Springer Science \& Business Media: Berlin/Heidelberg, Germany, 2012.

26. Dhimish, M.; Holmes, V.; Mather, P.; Sibley, M. Novel hot spot mitigation technique to enhance photovoltaic solar panels output power performance. Sol. Energy Mater. Sol. Cells 2018, 179, 72-79. [CrossRef]

27. Takagiwa, Y.; Shinohara, Y. A practical appraisal of thermoelectric materials for use in an autonomous power supply. Scr. Mater. 2019, 172, 98-104. [CrossRef]

28. Wen, Z.; Chen, J.; Cheng, X.; Niu, H.; Luo, X. A new and simple split series strings approach for adding bypass diodes in shingled cells modules to reduce shading loss. Sol. Energy 2019, 184, 497-507. [CrossRef]

29. Vieira, R.; de Araújo, F.; Dhimish, M.; Guerra, M. A Comprehensive Review on Bypass Diode Application on Photovoltaic Modules. Energies 2020, 13, 2472. [CrossRef]

30. Laamami, S.; Abid, A.; Benhamed, M.; Sbita, L. Investigation on Protection Diodes in PV Generator. In Proceedings of the 2020 17th International Multi-Conference on Systems, Signals \& Devices (SSD), Monastir, Tunisia, 20-23 July 2020; IEEE: Piscataway, NJ, USA, 2020; pp. 1069-1073.

31. Gallardo-Saavedra, S.; Karlsson, B. Simulation, validation and analysis of shading effects on a PV system. Sol. Energy 2018, 170, 828-839. [CrossRef]

32. Çelik, Ö.; Tan, A.; Inci, M.; Teke, A. Improvement of energy harvesting capability in grid-connected photovoltaic mi-cro-inverters. Energy Sources Part A Recover Util. Environ. Eff. 2020, 1-25. [CrossRef]

33. Falconar, N.; Beyragh, D.S.; Pahlevani, M. A novel control system for solar tile micro-inverters. In Proceedings of the 2018 IEEE Applied Power Electronics Conference and Exposition (APEC), Phoenix, AZ, USA, 4-8 March 2018; IEEE: Piscataway, NJ, USA, 2018; pp. 375-380.

34. Kabalc1, E. Review on novel single-phase grid-connected solar inverters: Circuits and control methods. Sol. Energy 2020, 198, 247-274. [CrossRef]

35. Yuan, J.; Blaabjerg, F.; Yang, Y.; Sangwongwanich, A.; Shen, Y. An Overview of Photovoltaic Microinverters: Topology, Efficiency, and Reliability. In Proceedings of the 2019 IEEE 13th International Conference on Compatibility, Power Electronics and Power Engineering (CPE-POWERENG), Sonderborg, Denmark, 23-25 April 2019; pp. 1-6.

36. Zhang, Z.; He, X.-F.; Liu, Y.-F. An Optimal Control Method for Photovoltaic Grid-Tied-Interleaved Flyback Microinverters to Achieve High Efficiency in Wide Load Range. IEEE Trans. Power Electron. 2013, 28, 5074-5087. [CrossRef]

37. Gao, W.X.; Wang, M.Y.; Wang, L.J.; Liu, Y. Review of research on photovoltaic micro-inverter. Power Syst. Prot. Contrl. 2012, 40, 147-155.

38. Gazis, F.S.; Vokas, G.A.; Katsimardou, I.J.; Kaldelis, J.K. Micro inverters for PV plants compared to the ordinary string or central inverters. In Proceedings of the Conference for International Synergy in Energy, Environment, Tourism and Contribution of Information Technology in Science, Economy, Society and Education, Piraeus, Greece, 23-25 September 2013; pp. 1-9.

39. Christabel, S.C.; Srinivasan, A.; Winston, D.P.; Kumar, B.P. Reconfiguration solution for extracting maximum power in the aged solar PV systems. J. Electrl. Eng. 2016, 16, 440-446.

40. Deshkar, S.N.; Dhale, S.B.; Mukherjee, J.S.; Babu, T.S.; Rajasekar, N. Solar PV array reconfiguration under partial shading conditions for maximum power extraction using genetic algorithm. Renew. Sustain. Energy. Rev. 2015, 43, 102-110. [CrossRef]

41. Lee, H.-S.; Yun, J.-J. Advanced MPPT Algorithm for Distributed Photovoltaic Systems. Energies 2019, 12, 3576. [CrossRef]

42. Lee, J.-H.; You, Y.-J.; Saeed, M.A.; Kim, S.H.; Choi, S.-H.; Kim, S.; Lee, S.Y.; Park, J.-S.; Shim, J.W. Undoped tin dioxide transparent electrodes for efficient and cost-effective indoor organic photovoltaics $\left(\mathrm{SnO}_{2}\right.$ electrode for indoor organic photovoltaics). NPG Asia Mater. 2021, 13, 43. [CrossRef] 